\title{
BRIEF NOTICES
}

\section{ERR A T A}

In Suzanne Romaine's article, "The relative clause marker in Scots English" (vol. 9, no. 2, August 1980), table 7 on page 234 should not indicate a $W$ in the genitive column for text C. On page 246 , footnote 31 was inadvertantly omitted. It is:

The development of WH relatives is of course motivated in part by purely syntactic principles; WH relative pronouns do not require stranding. The typological split between those Germanic languages which have invariant relative particles and those which do not also coincides with the incidence of proposition stranding. It appears that an indeclinable relative particle is a necessary precondition for stranding in relative clauses (cf. also Allen 1977: 355-56).

Susan Gal 's review of Howard Giles \& Robert St. Clair (eds.). Language and social psychology was published in a first version (vol. 9, no. 3, December 1980) and not as she revised it. The main substantive changes are these:

On page 372 , the sentence beginning in line 14 of paragraph 2 should read:

Unfortunately, although the social psychological theories discussed in this collection are potentially quite interesting for studies of language use, most of the analyses offer little that is enlightening.

In the same paragraph, line 8 from the bottom should include ".(e.g., Fishman 1972, Trudgill 1974)" after the words "class dialects."

On page 373, paragraph 2, the passage beginning with line 12 should read:

Very briefly, this view holds that individual motives and moods are communicated in speech by momentary deviations from the expected regularities. Unusual or marked stylistic choices must be heard and interpreted by participants in light of the expected or unmarked choices which are ordinarily taken to be appropriate to the particular context (e.g., Brown \& Gilman 1960, Blom \& Gumperz 1972). This view of marking as crucial to speech interpretation is not without its problems. A formal theory of this process has also been proposed (Geoghegan 1973). Nevertheless, it is part of a widely held conception of the cognitive processes involved in stylistic variation.

The references are:

Blom, J. P. \& Gumperz, J. J. (1972). Social meaning in linguistic structures: code-switching in Norway. In J. Gumperz and D. Hymes (eds.), Directions in sociolinguistics. New York: Holt, Rinehart, and Winston. 407-35.

Brown, R. \& Gilman, A. (1960). The pronouns of power and solidarity. In T. A. Sebeok (ed.), Style in language. Cambridge. Mass.: MIT Press. 253-76.

Fishman, J. (1972). Language maintenance and language shift as fields of inquiry: Revisited. In A. S. Dil (ed.), Language in socioculural change: Essays by Joshua A. Fishman. Stanford: Stanford University Press. 76-134.

Geoghegan, W. (1973). Natural information processing rules: Formal theory and application to ethography. Monograph 3. Language Behavior Research Laboratory, Berkeley, California.

Trudgill, P. J. (1974). The social differentiation of English in Norwich. Cambridge University Press.

Einar Haugen's review of Papers from the fourth Scandinavian conference of linguistics, Kirsten Gregersen et al., eds. (vol. 9, no. 3, December 1980), should have the last complete sentence on page 392 read as follows:

(C) I98 I Cambridge University Press 